\title{
Enhancing Learning through Community Membership: Honours Students' Perceptions of Community Membership and Its Impact on Learning
}

\author{
Paul Wabike (Corresponding author) \\ International Business School, Fontys University of Applied Sciences \\ P.O. Box 141, 5900 AC Venlo, The Netherlands \\ Tel: 31-640-299-9730Ｅ-mail: p.wabike@fontys.nl
}

Received: June 27, 2021 Accepted: August 10, 2021 Published: August 17, 2021

doi:10.5296/jei.v7i2.18814 URL: https://doi.org/10.5296/jei.v7i2.18814

\begin{abstract}
This article looks at how membership of a community impacts learning for individuals. Community membership and learning have received much attention from scholars and practitioners alike (for example, in Wolfensberger, 2012; Inkelas, Jessup-Anger, Wawrzynski, \& Benjamin, 2007; Wenger, 1998). Specifically, many studies have focused on learning communities and how membership in such a community can help individual learners achieve what they are pursuing (Gabelnick et al., 1990). Using Communities-of-Practice (CoP) theory (Lave \& Wenger 1991; Wenger, 1998) as a theoretical background, this study sought to understand the perceived impact of community membership on learning. The ultimate goal is to put the benefits and drawbacks of this membership in the perspective of a close-knit group of students who exist within a large school community. This study has several objectives:

(1) To understand the role of the community in learning for individual members.

(2) To enhance student learning that is facilitated through the presence of a community of practice.

(3) To establish how a CoP can create a conducive learning environment for community members.

This research article seeks to understand how community membership impacts learning through the perceptions of community members themselves. A questionnaire was sent out to 50 honours students (in the cohort 2016-2018), whereby 28 questionnaires were returned. The results show that community members experience a safe and supportive environment for their learning. The community can also be an exclusion factor from other communities, which can
\end{abstract}


be counterproductive in learning. The implications of these results are discussed, and suggestions are given for school administrators who would like to use a community in enhancing learning.

Keywords: Honours education, Honours community, Learning, Active participation, Communities-of-practice

\section{Introduction to Learning Communities and Honours Education}

Learning communities can act as hubs where people connect, share a vision, and collectively measure progress. In Higher Education (HE), learning communities have received a wide range of definitions and applications. For example, Gabelnick, MacGregor, Matthews, and Smith (1990) define learning communities as the "purposeful restructuring of the curriculum by linking courses that enrol a common cohort of students. This represents an intentional structuring of the students' time, credits, and learning experiences to build community, and foster more explicit connections among students, faculty, and disciplines". Zhao and Kuh (2004) assert that a learning community is a group of people engaged in intellectual interaction for learning. While this is true for the academic part of the membership of the honours programmes, the idea of the honours learning community goes beyond the intellectual side of interactions. There is a growing recognition that learning communities impact education acquisition by those involved in these communities. This notion has positively been related to students' learning and success (Rocconi, 2011; Wighting, Nisbet, \& Spaulding, 2009; Kuh, 2008; Zhao \& Kuh, 2004). Studies have highlighted the importance of learning communities as a medium to facilitate active and passive learning, teamwork and cooperation rather than competition, thus fostering a sense of community (Cross, 1998). Among others, studies have found evidence of the benefits of learning communities as being desired learning outcomes, satisfaction with the college, persistence and graduation, and achievement of better grades (West \& Williams, 2017; Preece, 2014; Inkelas et al., 2007; Knight, 2003). Other researchers have found a positive correlation between learning communities and good student-faculty interaction, interaction with peers, time spent on courses and other academic undertakings (Rocconi, 2011; Pike, Kuh, \& McCormick, 2008). Wolfensberger (2012) posits that a community can be where interactive teaching, learning and peer feedback combine to create a critical and significant learning environment. By doing so, members are constantly challenged to co-create that learning experience. These different activities add to community members' sense of belonging and interdependence (Preece, 2014). For example, McMillian and Chavis (1986) define a sense of community as having four primary attributes as having: (A) the feeling of belonging or sharing a sense of personal relatedness; (B) the influence: a sense of mattering, of making a difference to a group and of the group mattering to its members; (C) reinforcement: integration and fulfilment of needs. It is the feeling that members' needs will be met by the resources received through their membership in the group, and (D) shared an emotional connection: the commitment and belief that members have shared and will share history, common places, time together and similar experiences.

Although these attributes are commonly seen in many learning communities within higher 
education (West \& Williams, 2017), our understanding of the impact of belonging to this community on learning is limited. McMillian and Chavis (1986) advance the idea that part of benefiting from the community is active engagement and shared emotional connectedness, which increases a sense of belonging. It is this belonging to the honours community that McMillan and Chavis (1986) define a sense of community as being "a feeling that members matter to one another and to the group, and a shared faith that members' needs will be met through their commitment to being together".

Studies suggest that student participation and students' engagement levels impact educational outcomes (Wolfsenberger, 2012; Rocconi, 2011). Consequently, participation and engagement impact educational outcomes (Wighting et al., 2009; Pike et al., 2008). However, being a member of a learning community and the actual learning for the individual member is still unclear. Not belonging but actively participating in the community may have the desired benefits of being part of the learning community (Wighting et al., 2009). Because of the perceived benefits of being in a community, many studies have paid attention to community membership and the willingness to actively enhance learning (West \& Williams, 2017; Strom, 2011; Rocconi, 2011; Wenger, 1998). The evidence that learning communities enhance learning for individuals and allow for upscaling of best practices, school administrators and educators have deployed different measures and implemented policies that help design and create these communities (Rocconi, 2011; Pike et al., 2008; Knight, 2003). However, West \& Williams (2017) suggest that these benefits may be challenging to attain because 'researchers and practitioners use different terminology and frameworks for conceptualising the nature of learning communities'.

Wolfensberger (2012) suggests that "an honours community may be the best opportunity for academically gifted students to develop friendships and form social bonds while also satisfying their intellectual interest". Other studies have found a similar correlation (Lamb, Boedeker, \& Kettler, 2019; Van Heugten, Heijne-Penninga, Paans, \& Wolfensberger, 2016; Clark \& Zubizarreta, 2008). Although other studies do not specifically refer to honours education, they refer to learning communities within universities as enhancing the learning experience (Rocconi, 2011; Kuh, 2008; Ruben, 2007). Universities and other forms of higher education have employed efforts to create learning communities, such as honours education, to maximise the learning and the learning experiences. These communities typically offer an academic challenge not given in a regular classroom setting (Kaczvinsky, 2007, cited in Wolfensberger, 2012). Some scholars posit that honours students are more academically interested and receptive to new ideas than regular students (Wolfensberger, Drayer, \& Volker, 2014; Wighting et al., 2009). In this research, the CoP theory (Lave \& Wenger, 1991) is used as a theoretical foundation to understand how honours community members at the Hanze International Business School perceive the impact of community membership on their learning.

\subsection{Honours Education. In Search of Excellence?}

Different higher education systems around the World have implemented honours education to recognise individuals who demonstrate a depth of knowledge or originality. In other systems, 
an Honours degree is obtained after completing extra study load and after showing excellence in specific fields (England, 2010). For example, in the Netherlands, growing recognition of excellence in higher education has led to an increased establishment of honours programmes in many academic and applied sciences universities (Wolfsensberger, 2014). Honours education as systems within HE that seek to promote excellence among their students (Wolfensberger, Drayer, \& Volker, 2014). Honours programmes differ widely worldwide in the modes of delivery and organisation. They can be in the form of an honours college, honours programmes or honours courses. Both public and private institutions can offer honours education (England, 2010). In the United States, for example, The National Collegiate Honours Council (NCHC) coordinates undergraduate honours programmes and has more than 800 member institutions (Wolfensberger, 2012). In Australia, an honours education typically takes one to two years of research programme after finishing a bachelor's degree. In the United Kingdom (except for Scotland) honours, degrees are awarded after students complete an additional programme on their regular bachelor studies (Lamb et al., 2019). This system is similar to the Netherlands', where the programme is undertaken from the second year of a four-year bachelor programme (Van Heugten et al., 2016). In South Africa, an honours programme typically is a year after completion of a bachelor's degree. Further literature about honours is provided by the NCHC 2012 issue titled Honours Around the Globe.

The increase in recognition of honours education is associated with increased competition for excellent students and the realisation that some students may need a diverse, challenging environment than what is offered in regular non-honours education (Van Heugten et al., 2016; Clark \& Zubizarreta, 2008). Although honours education structures and delivery modes differ, the philosophy behind honours is the same (Brinkel, Rees, Ruis, \& Sloots, 2015). However, the term 'excellence' is in itself a subject of considerable debate among scholars and practitioners. The European Association for Quality Assurance in Higher Education (ENQA) (2014) asserts that excellence cannot be defined independently of other factors such as the motives of the one defining it, socio-cultural and economic influences, and institutional constraints within higher education. According to Ruben (2007), excellence has the purpose of establishing and maintaining an outstanding institution, department or programme. Honours programmes typically fall under this purpose. Defined within the realms of formal education settings, Wolfensberger et al. (2014) sum up excellence,

as the outcomes that result from received and analysed knowledge to the intensive investigation of issues and topics that are personally meaningful to the student (p. 12).

Excellence in honours education programmes can be defined primarily as demonstrating exceptional characteristics (ENQA, 2014). These programmes are often run in small groups of students who exhibit exceptional characteristics in their pursuit of academic excellence and personal growth. According to Wolfensberger (2012), honours programmes are designed for gifted and motivated students who are willing and able to do more than a regular programme offers, mainly looking at the academic challenge and the drive for personal development. Coupled with this is the intrinsic motivation that pushes these students to take on an extra workload. Clark and Zubizarreta (2008) have advanced the notion that honours programmes 
differ from regular courses because of an enhanced degree of openness, risk-taking, and challenge. This, according to Van Heugten et al. (2016), takes place when students are afforded the room and freedom to explore their talents. Although excellence can be defined in terms of global institution operations, this article defines excellence in relationship to honours education. This search for excellence that honours education and honours colleges have been developed to allow gifted students to flourish.

\subsection{Honours Education Context}

The International Business School is part of The Hanze University of Applied Sciences (HUAS), Groningen, The Netherlands. The school is dedicated to business and management studies taught in both English and German languages. In 2017, the school had about 1,400 students coming from more than 40 different nationalities. At the school, Honours Talent Programme was created based on the talent profile of Highly Talented International Business Professionals (HTIBP) (Van Heugten et al., 2016) and offered talented students an opportunity to explore other academic and non-academic fields not offered in the regular programme. It is an enhanced educational programme of 30 ECTS (ECTS = European Credit Transfer System. 1 ECTS equals 28 hours of course work) on top of the regular 180 ECTS Bachelor Programme.

There were 50 students in the honours programme at the end of 2017. Based on Wolfensberger (2012) definition of honours pedagogy, honours students are encouraged to interact; give each other feedback; share their ideas and show commitment to learning through knowledge sharing. They undertake challenging academic tasks such as interdisciplinary courses; embrace multiple perspectives, and challenge the status quo on academic and social issues. They are given a degree of freedom to make informed choices, experiment and be expressive of their views, and be open to different possible approaches to the same problem.

Honours students at this business school focus on five main content areas during their three years in the programme: Advanced Business Content; Seminars; Community; Interdisciplinary and Mentoring. These areas are structured around seminars, lectures, excursions and the attendance of a course at another institution. The Honours Talent Programme aims at helping talented students build upon their main phase of education to realise goals and skills beneficial for successful, advanced careers in their professional field. The main phase starts from the second year after students successfully complete a propaedeutic year in a four-year taught bachelor programme. The programme provides enrichment opportunities centred upon the student's purposes. It is designed to develop a depth of knowledge and skills in their chosen profession, explore interdisciplinary topics, and engage in the international community. Honours membership is voluntary; students in this community can leave the programme at any time if they wish to do so. The Honours Talent Programme also strengthens relationships and networks with its graduated students to maintain lifelong connections with the school as valued alumni.

Coordination of activities within the programme is done mainly by students under the supervision of staff. There is an honours board whose main aim is to establish a sense of 
community and open communication among honours students, mentors, business professionals, non-honours students, and alumni. The board is responsible for various tasks, including quarterly newsletters, social events, guest lectures and company visits. Honours students had a room within the business school. This room is a place to meet, work and relax. Community members have personalised the room and have knowledge exchange walls that link to what they learn throughout the three years in the programme-and after graduation. Events timetables, progress plans, projects, achievements and community activities are placed on the walls.

\section{Theoretical Note}

Communities of practices theory can be attributed mainly to Jean Lave and Etienne Wenger (Lave \& Wenger, 1991; Wenger, 1998). A community of practice (CoP) refers to a group of people who generate knowledge in the process of sharing their knowledge, experience, or insight on a common interest or a problem in a subject while they interact (Wenger, 1998). This particular common purpose brings people together to generate ideas or work on a project that is jointly accepted as being beneficial to the participating parties. The underpinning theoretical background of social learning is that learning is routinely centred on social experiences that individuals and communities share. It challenges the idea that learning is something fixed to a specific period and is undertaken by individuals for a particular purpose. Being a collective undertaking, learning is not seen as having" a beginning and an end; that it is best separated from the rest of our activities; and that it is the result of teaching" (Wenger 1998). Knowledge is acquired through complex human interactions within social networks, acquiring knowledge through shared experiences that constitute learning. Wenger (1998) posits that a CoP has three main dimensions: the joint enterprise (reasons for being together), mutual engagement (that binds the group together), and shared repertoire (communal resources such as routines, artefacts, vocabulary, and styles).

Lave and Wenger (1991) insist that there is no separation between learning and social practice and the context where they take place. Three main characteristics define a CoP according to Wenger (1998): the domain (activities that members share a concern about), the community (a group of people practising together) and the practice (interaction among community members). Communities-of-practice depends upon mutual engagement and patterns of shared meaning. In the broader context of negotiation, they are established via language and social relations and require both interpretation and action (practice) (Strom, 2011). A study conducted by Preece (2014) identified elements of learning that create these patterns of shared meaning leading to actions. Some of the study's findings were the importance of developing social contacts with fellow learners and how these contacts impacted learning as a practice. Items used in that study have been adopted in this study (please see 'Methodology' section).

\subsection{CoP, Learning and Honours}

The honours community at the business school was created as a separate domain within the large international business school domain. The honours programme forms a community and practices together in both academic and non-academic undertakings. The honours community 
meet regularly together both inside and outside the classroom. According to Lave and Wenger (1991), learning is "not merely situated in practice - as if it were some independently reifiable process that just happened to be located somewhere; learning is an integral part of generative social practice in the lived-in world". In this 'lived-in world', honours at the business school position learning as a process of (inter)action by encouraging the formation of community-of-practice. A CoP is created through mutual learning (Wenger, 1998), shared common concerns or passion for something, and regular interaction (Goddard, W. K. Hoy, \& A. W. Hoy, 2000). Members of a CoP do not necessarily need to have similar communal features regarding homogeneity, nor are they an idealised view of the community, but arise out of the mutual engagement that creates relationships among people as a result of sharing experiences (Ström, 2011). The practice gives meaning to what a group of people do. The development of practices takes time, and so is the learning process itself. For a community to establish certain practices, they need a "sustaining enough mutual engagement in pursuing an enterprise together to share some significant learning" (Wenger, 1998). These communities of practice are together based on the experiences individuals share through collective learning that is created over time through refining and defining what actions communities undertake. Smith (2009) asserts that the ability to undertake more extensive or more complex activities and projects through cooperation binds people together and helps to facilitate relationships and trust. This trust forms a vital part of learning. According to Wenger (1998), practice and community meet in two essential areas:

(a) It yields a tractable characterisation of the concept of practice-in particular, by distinguishing it from less tractable terms like culture, activity, or structure.

(b) It defines a special type of community-a community of practice.

This makes a practising community rather than a detached practice that takes place within a particular community. Ström (2011) sees practising together as what forms beliefs about what, within certain relationships, might work and what might not. This leads to what Wenger (1998) calls continuities or discontinuities of specific practices within communities. The belief that a community knows what works and what does not work further cement the idea that working together yields more results than what would be achieved by individuals on their own. Moreover, community members learn from each other (Smith, 2009) and thus, practising as a community strengthens certain learning practices. Preece (2014) discovered that students who had regular contacts with peers and shared practices about their education had a greater sense of belonging to a community than those who did not. Equally, in the same study, students indicated that this sense of belonging helped them perform better in their studies.

The strengths of this theory lie in the fact that it helps identify the learner as a 'whole being'. It is practically challenging to exclude the learner from their social setting and their associated meanings with the World around them. Learning is acquired through participatory social processes and should not be seen as a separate activity to gain abilities, skills and knowledge.

While the theory remains an essential source for educators and practitioners alike, there are 
issues unresolved relating to membership of a CoP. The treatise that learning takes place within the domain due to members sharing experiences does raise questions about whether learning takes place only within that domain. Membership can also be an excluding factor for those who feel they do not belong to a whole or part of a community, resulting in elitism where members belonging to that community acquire the knowledge while others do not (Ström, 2011). Those outside the group may also find it challenging to enter the closed circuit to enjoy learning within a community. According to Hodkinson and Hodkinson (2004), membership does not always mean 'value', and it can be of little to no value for some members. Apprenticeship-like learning may probably work better in a less complex work environment.

\section{Methodology}

An online survey was used to collect data. A mixed-methods survey using a questionnaire (quantitative) and open-ended questions (qualitative) was employed. The mixed-method approach explored the phenomenon 'community and learning in honours education. Creswell (2003) posits that this may help explain a phenomenon in depth by triangulation-where a qualitative method was used in this study to confirm and cross-validate findings obtained from a quantitative method.

A total population sampling method was used because the population size is small (50 people in total). Sample selection is based on membership to the Honours community at the time of the study. For students, membership of the business school honours community is given to anyone who fulfils three main selection criteria. One, their academic performance before joining honours (averaging 7 or higher). [The Dutch higher education uses a 10-point system for assessments, with one being the lowest and ten the highest. A 5.5 (and sometimes a 6) is a minimum pass]. The other two criteria are creative thinking and self-reflection. In the admission process, interviews, problem-solving in a group, and written evidence on solving different tasks are used as instruments for recruitment. For faculty, completion of year-long training on working with talents is required. Involved subjects could opt out of the study whenever they wished to do that.

The survey instrument was divided into two main parts: the first part, based on Preece (2014) and using CoP theory elements, collected perceptions and understanding of the community using a Likert-scale format, with four sections: (1) learning practices; (2) community; (3) process of becoming/identity formation; (4) meaning-making. Every section had items varying from five to eight with three mutually exclusive choices: never, rarely, and often. Data analysis is based on $\mathrm{N}=28$ as $100 \%$, reflecting the 28 respondents who fully completed the survey.

The second part consisted of three open questions that limited respondents to three responses only per question. This part summed up perceptions of the advantages and disadvantages of belonging to this community concerning learning. The survey was anonymously administered; no personal data were collected. Data were then categorised into themes, and then key phrases were extracted from the categorised data and used as supporting evidence in the analysis. 


\section{Questionnaire Results}

Of the 50 total honours community students at the International Business School, 28 responses were returned, representing a return rate of $56 \%$ of all surveyed students. Results are discussed briefly here below.

Table 1. Learning practices

\begin{tabular}{|l|l|l|l|l|}
\hline Item & Never & Rarely & Often & Total \\
\hline I discuss work with other community members when outside school & 0 & 5 & 23 & 28 \\
\hline $\begin{array}{l}\text { I discuss concepts and other academic issues with other community members } \\
\text { outside of class }\end{array}$ & 0 & 6 & 22 & 28 \\
\hline $\begin{array}{l}\text { I interact with the other community members who are not in my study year } \\
\text { (cohort) to compare experiences }\end{array}$ & 1 & 8 & 19 & 28 \\
\hline $\begin{array}{l}\text { My education progress is influenced positively by working with community } \\
\text { members }\end{array}$ & 0 & 6 & 22 & 28 \\
\hline $\begin{array}{l}\text { I bring in and share knowledge from elsewhere } \\
\text { I form sub-groups within the community members to discuss my work }\end{array}$ & 2 & 8 & 18 & 28 \\
\hline I share my progress with the group & 2 & 12 & 14 & 28 \\
\hline I find it easier to work with other students than those in the community & 16 & 11 & 1 & 28 \\
\hline
\end{tabular}

Discussions inside and outside the classroom constitute a high level of involvement for group projects honours students are involved in (82\%). Almost $80 \%$ of the students feel that their educational progress is positively influenced by working with community members. $82 \%$ share knowledge gained from elsewhere with community members, and they share experiences from community members who are not in their study year (64\%). Group forming within the community often happens as $64 \%$ suggests members often form sub-groups, and $28.5 \%$ do that rarely as opposed to only $7 \%$ who never form sub-groups. However, only $60 \%$ of honours students feel comfortable sharing their progress within the community. Only $3.5 \%$ (representing one response) often feels comfortable sharing work and social life events and experiences with other students outside the community. 
Table 2. Community

\begin{tabular}{|l|l|l|l|l|}
\hline Item & Never & Rarely & Often & Total \\
\hline I now mix with people I did not know at the beginning & 0 & 4 & 24 & 28 \\
\hline I share my experiences with the community members & 1 & 3 & 24 & 28 \\
\hline I socialise with my classmates who are in the community & 1 & 3 & 24 & 28 \\
\hline I socialise with other students (not classmates) who are in the community & 2 & 9 & 17 & 28 \\
\hline I only mix with people I knew before I joined the community & 16 & 10 & 2 & 28 \\
\hline I feel the community becoming too closed that it hinders knowledge growth & 16 & 11 & 1 & 28 \\
\hline $\begin{array}{l}\text { I have no time to socialise with other students because there are too many } \\
\text { activities within the community }\end{array}$ & 10 & 16 & 2 & 28 \\
\hline
\end{tabular}

The honours community has specific practices that glue the community into one domain. The first three questions in the item 'community' return $96 \%$ of the students who find it easier to work with students from the community than with regular students. The above set of questions also shows that most honour students are involved in the community on a social level. They socialise with: students they did not know before joining the community, students from the community in their class, and students in the community who are not in their class. However, attending a social event is not limited to the community members only as $60 \%$ socialise with students outside the community.

A combined $42.5 \%$ of the community members rarely or often feel that the community is becoming too closed, hindering their knowledge growth, while 57\% never have that feeling. Also, $65 \%$ of respondents feel that they rarely or often have no time left to socialise with other students because activities within the community demand time.

Table 3. The process of becoming/identity formation

\begin{tabular}{|l|l|l|l|l|}
\hline Item & Never & Rarely & Often & Total \\
\hline I feel my experiences are of value to others in the community & 1 & 9 & 18 & 28 \\
\hline I see the relationship between what other honours students do and what I do & 2 & 4 & 22 & 28 \\
\hline I now use jargon words related to honours more comfortably in discussions & 5 & 11 & 12 & 28 \\
\hline I can genuinely say I belong to the honours community & 1 & 3 & 24 & 28 \\
\hline $\begin{array}{l}\text { I see the difference between being in the honours community and being in the } \\
\text { regular class }\end{array}$ & 0 & 1 & 27 & 28 \\
\hline $\begin{array}{l}\text { Members of the community challenge me to better my academic and } \\
\text { non-academic activities }\end{array}$ & 1 & 10 & 17 & 28 \\
\hline $\begin{array}{l}\text { I now care more about comments made/advice given by community members } \\
\text { than other business school students }\end{array}$ & 3 & 13 & 12 & 28 \\
\hline
\end{tabular}


Identity forming is a significant part of forming a community's norms and values. $85 \%$ of the students truly feel part of the Honours community, with $42.8 \%$ feeling comfortable using honours jargon within the community compared to the $39 \%$ (rarely) and $17.8 \%$ (never) who experience difficulties in using the jargon. $42.8 \%$ care more about comments made or advice given by community members than those outside the community (11\%). To show the strength of being in a community, $96 \%$ of the students often see the difference between being in the community and being in the regular class. A $60 \%$ of community members often feel challenged by other community members to improve their academic and non-academic activities. In comparison, $35 \%$ rarely feels they are being challenged enough by having a community membership.

Table 4. Meaning-making

\begin{tabular}{|l|l|l|l|l|}
\hline Item & Never & Rarely & Often & Total \\
\hline I contribute to group feedback during community members' presentations & 0 & 10 & 18 & 28 \\
\hline I refine my own understandings as a result of class feedback & 1 & 4 & 23 & 28 \\
\hline I use my own experiences to inform or critique members' work & 0 & 7 & 21 & 28 \\
\hline I try out new ideas with others in the group & 0 & 11 & 17 & 28 \\
\hline I feel I understand what community members are trying to do/say & 1 & 3 & 24 & 28 \\
\hline
\end{tabular}

From this set of questions, responses show that students can give meaning to concepts presented by community members and the honours programme in general. They contribute to group feedback (64\% often and $35.7 \%$ rarely) and can refine their understanding as a result of class feedback (82\%). Respondents understand what community members are saying $(85.7 \%)$, while $75 \%$ feel the freedom to critique other members' contributions to the community. $60.7 \%$ feel comfortable trying out new ideas with other community members, followed by $39.3 \%$ who rarely try new ideas within the community. The following sections represent qualitative responses to the study.

\subsection{Advantages of Being in the Honours Community}

Respondents indicated that membership to the honours community comes with many new opportunities that inspire them to explore different academic and personal developments. These opportunities are typically not offered in the main phase. Here are some of what respondents said:

Chance to take on challenges not offered in the main phase.

Learning goes beyond the regular syllabus.

New inspirations through seminars and mentoring. 
Room to challenge yourself.

Likewise, they identify what those opportunities mean for their learning:

The high standards of the Honours Community improve my development.

Opens up new horizons and perspectives in a more professional way.

New opportunities to further improve my professional life.

Personal growth.

It helps me stay open-minded and explore new ideas.

Exploring new ideas came up in some of the themes arising from the findings' freedom to explore', 'challenging environment', and 'sense of being in a community' where one can feel comfortable learning. Data analysis shows that a 'sense of being in a community', with the word 'help' recurring, is found particularly important by honours students. Furthermore, there is a consensus about the communal spirit inside the community, which creates a safe enough environment to explore new ideas. Respondents had this to say:

Getting help whenever needed from anyone in the community.

Helping each other out as much as possible.

You get help from the whole group, and I truly believe you achieve more with a group.

Students work in a group of people they come to know well in the three years they spend in the community. This was further evident as respondents appreciated the fact that community members are similar to some extent in their journey of talent development. The quotes here below reflect how belonging to a community acts as motivation for learning:

Everyone has a similar mind-set/motivation.

Same minded people.

Like-minded people who are eager to develop themselves further.

You get motivated through being in an environment with ambitious persons.

Similar to the responses above, making new friends and finding a place where community members feel comfortable and understood were essential factors. Respondents believed that identifying whom one can rely on in a large group is an essential aspect of community life. Meaning-making and identity formation contribute to the benefits of being in a community concerning learning.

Community itself: nice activities, feeling "at home”.

You feel a sense of belongingness, and everyone is welcoming and so incredibly nice.

Family feeling in an anonymous university atmosphere.

A strong group of friends whom I can trust and rely upon on both the good and the bad 
days!

It is not always necessary that all members possess skills to perform specific tasks that make community membership valuable. Responses show that the level of acceptance members enjoy may spur them to acquire more skills and improve task performance by learning new skills. A respondent mentioned this particular community spirit that best describes the sense of community at the business school:

One is accepted with the skills one has, not rejected because of the skills one lacks.

\subsection{Disadvantages}

Respondents also indicated how a community could hinder learning. Some respondents believed that their educational progress is rarely positively influenced by working with community members. They do not always wish to share their progress with the rest of the members. Some of the frustrations of working within the community are:

Unequal contribution of certain members.

Lack of motivation/involvement from some students.

Community learning here is seen as a process involving willingness to share one's knowledge, thereby contributing to learning. Responses indicate that there is little room for improving how tasks are performed when community members do not contribute or freely critique each other's work. In connection with this, respondents felt belonging to the group, and the exclusive nature of being an honours student added more pressure to try and conform to group rules, even when it was not suiting individual needs:

Pressure to be a community even when it doesn't happen naturally.

The community could be a closer group in my opinion.

Cannot identify myself with all members.

The stigma of honours.

The pompous behaviour of others within the community.

Although new opportunities inspire joint explorations and learning, respondents mentioned the stress associated with an extra workload that leaves little room for social activities. These opportunities are not extra-curricular activities; students earn educational credits, thereby adding extra pressure to perform in those honours activities. This, however, does not include social events. Some of the respondents mentioned:

Less time for other friends and free time activities.

Additional high workload.

Decreasing grades in the main phase.

Less time with family. 
Takes up more time than expected.

More work. Sometimes overwhelming.

Large pressure of performing and living up to standards.

A recurring theme is how students feel isolated from the rest of the business school community. Respondents mentioned perceived prejudices from regular business school students and a negative image towards the honours community. Honours community members do not always feel accepted by their fellow students and lecturers who are not part of the community:

We as students are sometimes treated differently by lecturers or fellow students that are not part of the honours.

Some regular students are negatively biased against the community.

The behaviour of a single person can have a bad effect on the community and how it is seen.

The community image is not always accepted by other students and teachers.

Some students also portray a feeling of isolation that occurs through being part of the Honours Community.

Isolation, through more communication within the community than with regular students.

Honours community is sometimes a bit isolated. (For example by spending a lot of time in the honours room).

Sometimes (i.e. in regular classes) the community members do not mingle enough with the other students.

\section{Discussion}

There is a link between students' perception of belonging to a community and how this community membership influences their learning. Many respondents indicated that learning is a practice as they share, critique, comment, and advise each other. As the results show, the domain at the business school in which students operate and a community with its rules and regulations help honours community members engage in learning. As stated earlier, being a community member does not necessarily constitute learning (Rocconi, 2011; Wighting et al., 2009; Pike et al., 2008), but being an active participant, taking ownership of the process within a community (West \& Williams, 2017; Preece, 2014). The community seems to function as both a safe place and, at the same time, a challenging one for honours community members to thrive.

Community learning is enhanced by understanding the domain within which community members practice (Lave \& Wenger, 1991). A community is not merely a club of friends or a loose network of connections between a group of honours students. It has a shared domain of interest that strengthens identity, creates friendship, and increases exploration freedom. The 
literature suggests that this freedom to explore is what talented students need to seek their capacity limitations and encourage them to achieve good results (Van Heugten et al., 2016).

Joint activities and belonging further enhance learning through task commitment and a need for a community that shares values and understanding. Just as Brinkel et al. (2015) and again Cross (1998) found out, sharing values in commitment to a task may spur collective learning, thereby strengthening community commitment (McMillan \& Chavis, 1986). To pursue their interest in the domain, members of the honours community engage in joint activities and discussions, as Wenger (1998) stated. This is further evident in the discussed disadvantages of being in a community. The lack of these joint activities or weak commitment can erode belonging and hamper learning efforts. Advantages of learning together were identified as being helpful to one another, sharing information, trusting that other members are committed, and strong relationships that enable learning from each other. Students agree that it is unnecessary to work together daily; what matters most is meeting regularly to achieve common goals and enhance knowledge. The dangers of a closely-knit group include being isolated from other groups, leading to an uneasy relationship with the regular business school community.

A practice (shared learning, shared repertoire) seems to be crucial to community learning. Honours students believed that having a common practice increases a sense of belonging and the need to work together to better this practice. This community is not a coalition of people who only share common interests; they are dynamic persons who meet to put their interests into practice. As results show, embracing differences while working towards the same goal is an added stimulus for learning.

There are several limitations to this study. There is no clear link as to whether community members learn more than they would do in a regular classroom. The only link found here is the increased specific activities honours community members have to perform. Seeking new challenges and the need to achieve more could result from exposure rather than having a community such as the honours one. Could regular students achieve the same if similar opportunities were presented to them? More studies are needed to substantiate this. Also, the sample studied is in one specific place and within a specific school (International Business School). There are questions about whether the same results can be achieved in a different school with different settings and resources endowment. Finally, there is a question of time. Although the longer the honours community members practice together, the better they understand each other, there were no apparent differences in learning experiences between senior community members (year four) responses and those with one to two years of working in this group.

\section{Conclusion}

This study sought to understand students' perceptions of the impact of community membership on learning. The results also indicate how active participation and the feeling of being accepted enhance that learning experience. Data obtained from this small-scale research shows that there are many intersections of actions and thoughts as a team of students work together within a community. This study showed that membership to a community, to 
some extent, increases the chances of community members to learn and be challenged to achieve results. The study also showed that active participation has a more significant impact on learning than mere membership. With much of the education provision at the university involving group work, understanding the impact of a community in learning is an essential aspect of enhancing learning experiences. Such a learning context may advance the notion that forming learning groups may help students create a supportive learning environment that, in turn, enriches their learning experience.

School administrators could find it helpful to create communities of learners to inspire a sense of belonging and ownership, thus enhancing learning opportunities. The results can also be applied by students who perceive the benefits and advantages of learning in a community to reduce group pressures and create working networks enabling students to explore knowledge beyond the syllabus. Although it is practically impossible to offer an exceptional education, attention to individual needs and the feeling of being part of a broader meaningful community can add to the learning. Learning is not an isolated activity. It is embedded in experience, meaning that creating a conducive learning environment (in terms of communities) can benefit even those who do not necessarily ascribe to the role of a community member in learning.

\section{References}

Brinkel, N., Rees, F. V., Ruis, M., \& Sloots, F. (2015). Community Building at Honors Programs in Continental Europe. Honours in Practice, 11, 93-109.

Clark, L., \& Zubizarreta, J. (2008). Inspiring exemplary teaching and learning: perspectives on teaching academically talented college students. Lincoln, NE: NCHC.

Creswell, J. W. (2013). Research design: Qualitative, quantitative, and mixed methods approaches. Sage Publications, Incorporated.

Cross, K. (1998). Why learning communities? Why now? About Campus, 3(3), 4-11. https://doi.org/10.1177/108648229800300303

England, R. (2010). Honors programs in four-year institutions in the northeast: A preliminary survey toward a national inventory of honors. Journal of the NCHC, 11(2), 71-82.

Gabelnick, F., MacGregor, J., Matthews, R., \& Smith, B. (1990). Learning communities: Creating connections among students, faculty, and disciplines. New Directions for Teaching and Learning (No. 41). San Francisco: Jossey-Bass. https://doi.org/10.1002/t1.37219904102

Goddard, R., Hoy, W. K., \& Hoy, A. W. (2000). Collective Teacher Efficacy: Its meaning, measure and impact on student achievement. American Educational Research Journal, 37(2), 479-507. https://doi.org/10.3102/00028312037002479

Hodkinson, P. M., \& Hodkinson, H. D. (2004). The significance of individuals' dispositions in workplace learning: a case study of two teachers. Journal of Education and Work, 17(2), 167-182. https://doi.org/10.1080/13639080410001677383

Inkelas, K. K., Jessup-Anger, J., Wawrzynski, M., \& Benjamin, M. (2007). Living-Learning 
Programs that Work: A Research-Based Model for Design, Delivery, and Assessment. San Francisco: Stylus Publishing, LLC.

International Business School. (2015). Honours Talent Programme. Retrieved from https://blackboard.hanze.nl/webapps/blackboard/execute/announcement?method=search\&con text $=$ course_entry\&course_id=_254636_1\&handle=announcements_entry\&mod=view

Knight, W. E. (2003). Learning communities and first-year programs: Lessons for planners. Planning for Higher Education, 31(4), 5-12.

Kuh, G. D. (2008). High-impact educational practices: What are they, who has access to them, and why they matter. Washington, D.C: Association of American Colleges and Universities.

Lamb, N., Boedeker, P., \& Kettler, T. (2019). Inequities of Enrollment in Gifted Education: A Statewide Application of the 20\% Equity Allowance Formula. Gifted Child Quarterly, 63(4), 205-224. https://doi.org/10.1177/0016986219830768

Lave, J., \& Wenger, E. (1991). Situated learning: Legitimate peripheral participation. New York: Cambridge University Press. https://doi.org/10.1017/CBO9780511815355

McMillan, D. W., \& Chavis, D. M. (1986). Sense of community: A definition and theory. Journal of Community Psychology, 14(1), 6-23. https://doi.org/10.1002/1520-6629(198601) 14:1\%3C6::AID-JCOP2290140103\%3E3.0.CO;2-I

Pike, G., Kuh, G., \& McCormick, A. (2008). Learning Community Participation and Educational Outcomes: Direct, Indirect, and Contingent Relationships. Paper presented at the Annual Meeting of the Association for the Study of Higher Education, Jacksonville, FL.

Preece, J. (2014). PhD study in South Africa as a community of practice: Benefits and challenges. International Journal of Continuing Education and Lifelong Learning, 6(2), 41-58.

Rocconi, L. M. (2011). The impact of learning communities on students' growth and development. Research in Higher Education, 52(2), 178-193. https://doi.org/10.1007/ s11162-010-9190-3

Ruben, B. D. (2007). Excellence in Higher Education Guide. An integrated Approach to Assessment, Planning, and Improvement in Colleges and Universities. Washington D.C.: National Association of College and University Business Officers.

Ström, J. A. (2011). Enabling engagement: A study of university-community engagement at a non-metropolitan Australian university. (Doctoral dissertation, Southern Cross University, Lismore, New South Wales).

Van Heugten, P., Heijne-Penninga, M., Paans, W., \& Wolfensberger, M. (2016). Characteristics of highly talented international business professionals defined. European Journal of Training and Development, 40(2), 58-73. https://doi.org/10.1108/EJTD-042015-0032 


\section{Macrothink}

Wenger, E. (1998). Communities of practice: Learning, meaning, and identity. Cambridge, UK: Cambridge University Press. https://doi.org/10.1017/CBO9780511803932

West, R. E., \& Williams, G. S. (2017). I don't think that word means what you think it means. A proposed framework for defining Learning Communities. Educational Technology Research and Development, 65, 1569-1582. https://doi.org/10.1007/s11423-017-9535-0

Wighting, M., Nisbet, D., \& Spaulding, L. (2009). Relationships between Sense of Community and Academic Achievement: A Comparison among High School Students. The International Journal of the Humanities, 7(3), 62-72. https://doi.org/10.18848/1447-9508/ CGP/v07i03/41368

Wolfensberger, M. V. C. (2012). Teaching for excellence. Honours Pedagogies revealed. Munster: Waxmann Verlag GmBH (A PhD thesis).

Wolfensberger, M. V. C., Drayer, A. L., \& Volker, J. J. M. (2014). Pursuit of Excellence in a Networked Society-Theoretical and Practical Approaches. Münster: Waxmann Verlag $\mathrm{GmBH}$.

Zhao, C., \& Kuh, G. D. (2004). Adding value: Learning communities and student engagement. Research in Higher Education, 45(2), 115-138. https://doi.org/10.1023/B:RIHE.0000015692. 88534.de

\section{Copyright Disclaimer}

Copyright for this article is retained by the author(s), with first publication rights granted to the journal.

This is an open-access article distributed under the terms and conditions of the Creative Commons Attribution license (http://creativecommons.org/licenses/by/3.0/). 